\title{
EFEKTIVITAS SPHYGMOMANOMETER ANEROID MODIFIKASI SEBAGAI ALAT UKUR TEKANAN HIDROSTATIS DAN IMPLEMENTASINYA SEBAGAI ALAT PERAGA
}

\author{
Dita Woro Wulandari ${ }^{1}$ *, Eko Swistoro $^{2}$, Connie $^{2}$ \\ ${ }^{1}$ Pascasarjana Pendidikan IPA FKIP Universitas Bengkulu, Bengkulu \\ ${ }^{2}$ Pendidikan Fisika FKIP Universitas Bengkulu, Bengkulu \\ *Email: ditaworowulandari46@gmail.com
}

\begin{abstract}
ABSTRAK
Penelitian ini bertujuan untuk memodifikasi alat sphygmomanometer, mengukur tekanan zat cair air dan minyak goreng pada alat sphygmomanometer aneroid modifikasi, menemukan efektivitas sphygmomanometer aneroid modifikasi sebagai alat ukur tekanan hidrostatis, menjelaskan peningkatan hasil belajar kognitif dan perbedaan hasil belajar antara siswa yang belajar menggunakan model pembelajaran inkuiri terbimbing dan siswa yang belajar secara konvensional. Populasi penelitian adalah seluruh siswa kelas VIII MTS Al-quran Harsallakum kota Bengkulu T/A 2016/2017. Sampel diambil dengan teknik sampling purposive, yaitu kelas VIIIE sebagai kelas eksperimen yang diajar dengan model pembelajaran inkuiri terbimbing dan kelas VIIID sebagai kelas kontrol yang diajar dengan pembelajaran konvensional. Desain penelitian yang digunakan adalah nonequivalent control group design. Hasil penelitian menunjukkan sphygmomanometer aneroid dapat dimodifikasi untuk mengukur tekanan air dan minyak goreng; nilai tekanan hidrostatis air dan minyak terbesar berada pada kedalaman $40 \mathrm{~cm}$ dengan besar tekanan masing-masing secara berurutan $3982,8 \mathrm{~N} / \mathrm{m} 2$ dan $3166,8 \mathrm{~N} / \mathrm{m} 2$, sedangkan nilai tekanan hidrostatis air dan minyak terkecil berada pada kedalaman $20 \mathrm{~cm}$ dengan masing-masing besar tekanan secara berurutan 1981,7 N/m2 dan 1573,7 N/m2; hasil uji Mann Whitney alat sphygmomanometer aneroid modifikasi efektif sebagai alat ukur tekanan, dengan nilai asymp.sig lebih kecil dari taraf signifikasi 0,05; terdapat peningkatan hasil belajar siswa dengan nilai $\mathrm{N}$-gain kelas ekperimen sebesar 0,65 (sedang) dan N-gain kelas kontrol sebesar 0,53 (sedang); terdapat perbedaan hasil belajar antara siswa kelas eksperimen dengan siswa kelas kontrol ditunjukkan pada hasil uji Mann whitney nilai asymp.sig 0,028 lebih kecil dari taraf signifikansi 0,05.
\end{abstract}

Kata kunci: Sphygmomanometer aneroid; model pembelajran inkuiri terbimbing; hasil belajar siswa

\section{PENDAHULUAN}

Sphygmomanometer aneroid dapat memberikan pengukuran yang akurat dan aman. Sphygmo-manometer aneroid ini lebih aman karena tidak menggunakan air raksa melainkan dengan menggunakan putaran berangka atau jarum penunjuk yang terdapat pada meteran bulat (Campbell et al, 2000, Canzanello et al. 2001, Fisher, 1978). Bailey, et al (1991) menyatakan bahwa Spigmo-manometer aneroid merupakan salah satu jenis alat pengukur tekanan darah secara manual. Tensimeter Aneroid umumnya terdiri dari meteran pengukur tekanan, balon pompa, serta selang yang tersambung ke manset. Hasil pengukuran dapat diketahui dari angka yang ditunjukkan oleh jarum pada meteran yang berbentuk bulat.

Kametas, et al (2006) dalam penelitiannya menyimpulkan bahwa sphygmomanometer aneroid baik dalam memberikan metode yang sederhana dan akurat untuk mengukur tekanan darah. Prinsip kerja sphygmomanometer aneroid menggunakan prinsip fisika yakni tekanan, dengan adanya prinsip tekanan pada alat ini, sphygmo-manometer aneroid dimodifikasi sehingga dapat digunakan untuk mengukur tekanan fluida lain selain darah seperti pada air dan minyak.

Hasil pengukuran tekanan zat cair yang didapat dari alat sphygmo-manometer ini diuji efektivitasnya. Uji efektivitas bertujuan untuk 
mengetahui kelayakan alat sphygmomanometer ini sebagai alat ukur tekanan hidrostatis. Setelah teruji efektivitasnya, alat sphygmomanometer ini diterapkan pada pembelajaran yang berfungsi sebagai alat peraga.

Aziz et al, (2006) menyatakan salah satu faktor penting yang mendukung proses pembelajaran IPA agar penyampaian konsep lebih baik yaitu dengan menggunakan media pembelajaran, salah satunya berupa alat peraga. Alat peraga adalah alat bantu yang digunakan oleh guru dalam proses belajar mengajar agar proses belajar siswa lebih efektif dan efisien. Kegiatan percobaan dengan menggunakan alat peraga juga akan memudahkan siswa untuk memahami materi yang bersifat abstrak menjadi lebih konkrit . Berdasarkan tanya jawab langsung dengan salah satu guru IPA di MTS Al-Quran Harsallakum kota Bengkulu, didapat kesimpulan bahwa alat peraga dalam pembelajaran masih sangat minim. Guru IPA biasanya hanya menggunakan media pembelajaran berupa buku, papan tulis dan menggunakan metode demonstrasi. Minimnya fasilitas alat peraga ini menyebabkan kurangnya tingkat pemahaman siswa pada konsep yang bersifat abstrak, seperti pada materi tekanan hidrostatis. Pada pembelajaran IPA konsep tekanan hidrostatis, keterbatasan alat peraga dapat diatasi dengan menerapkan sphygmomanometer aneroid modifikasi yang telah diuji efektivitasnya. Dengan adanya alat peraga ini diharapkan konsep tekanan hidrostatis dapat dipahami dengan mudah.

Menurut Zurkanain \& Suliyanah (2014), pemahaman tentang konsep IPA agar dapat dipahami dengan baik oleh siswa, maka pengajaran harus dititikberatkan pada peran siswa secara aktif, dan peran guru sebagai fasilitator, motivator, , maupun pemberi inspirasi. Upaya untuk meningkatkan keaktifan siswa dalam pembelajaran adalah dengan guru dapat menentukan sistem pengajaran yang tepat dan sesuai dengan pokok bahasan, kemampuan siswa, dan tujuan yang hendak dicapai. Salah satu upaya yang dapat dilakukan yaitu dengan menerapkan model pembelajaran inkuiri terbimbing.

Menurut Sanjaya (2007), Pembelajaran inkuiri terbimbing dirancang untuk mengajak siswa secara langsung mencari dan menyelidiki suatu konsep dalam proses ilmiah. Secara umum, inkuiri merupakan proses yang bervariasi dan meliputi kegiatan mengobservasi, merumuskan pertanya-an yang relevan, mengobservasi buku dan sumber-sumber informasi yang lain secara kritis, merencanakan penyelidikan atau investigasi, mereview apa yang telah diketahui, melaksanakan percobaan dengan menggunakan alat. Sebagai penunjang penerapan model inkuiri terbimbing, pada kegiatan eksperimen menggunakan alat peraga sphygmomanometer aneroid modifikasi.

Berdasarkan uraian diatas penelitian yang dilakukan yakni mengetahui efektivitas sphygmo-manometer aneroid modifikasi sebagai alat ukur tekanan hidrostatis dan penggunaannya sebagai alat peraga pada konsep tekanan hidrostatis dengan model pembelajaran inkuiri terbimbing. Penelitian ini dilaksanakan di MTS Al-Quran Harsallakum Kota Bengkulu.

\section{METODE PENELITIAN}

Penelitian yang dilakukan bertujuan untuk memodifikasi alat sphygmo-manometer aneroid sehingga dapat digunakan untuk mengukur tekanan zat cair (air dan minyak goreng), untuk mengukur tekanan zat cair air dan minyak goreng serta untuk menemukan efektivitas sphygmo-manometer aneroid modifikasi sebagai alat ukur tekanan hidrostatis. Penelitian ini dilaksanakan di Laboratorium MTS Al-Quran Harsallakum kota Bengkulu pada tanggal 1-15 Maret 2017. Setelah data nilai tekanan zat cair (air dan minyak goreng) diperoleh dan efektivitas sphygmomanometer aneroid modifikasi sebagai alat ukur tekanan hidrostatis telah teruji, penelitian dilanjutkan dengan mengimplemen-tasikannya dalam pembelajaran yang bertujuan untuk menjelaskan peningkatan hasil belajar kognitif siswa yang belajar menggunakan model pembelajaran inkuiri terbimbing dan siswa yang belajar secara konvensional serta untuk menjelaskan perbedaan hasil belajar antara siswa yang belajar menggunakan model pembelajaran inkuiri terbimbing dengan siswa yang belajar secara konvensional di MTS Al-Quran Harsallakum kota Bengkulu pada tanggal 16-3 April 2017. 
Populasi penelitian ini adalah seluruh siswa kelas VIII MTS Al-quran Harsallakum kota Bengkulu tahun pelajaran 2016/2017. Sampel diambil dengan teknik sampling purposive, yaitu kelas VIIIE sebagai kelas eksperimen yang diajar dengan model pembelajaran inkuiri terbimbing dan kelas VIIID dan sebagai kelas kontrol yang diajar dengan pembelajaran konvensional. Desain penelitian yang digunakan adalah nonequivalent control group design.

\section{HASIL DAN PEMBAHASAN}

Sphygmomanometer aneroid telah dimodifikasi sehingga dapat digunakan untuk mengukur tekanan zat cair selain darah. Zat cair yang digunakan dalam penelitian ini adalah air dan minyak. Alat-alat yang digunakan dalam penelitian ini yakni satu set sphygmomanometer aneroid, pipa Y berdiameter $7 \mathrm{~mm}$ sebagai pipa penghubung, selang karet lentur sebanyak 3 buah, pipa kaca dengan diameter $7 \mathrm{~mm}$, gelas ukur dengan kedalaman $40 \mathrm{~cm}$ dan penyangga alat. Dari satu set sphygmomanometer aneroid yang digunakan hanya pompa udara dan penunjuk skala tekanan.Penyangga alat terbuat dari kayu yang terdiri dari dudukan alat dan tiang penyangga kayu. Luas dudukan alat adalah $345 \mathrm{~cm} 2$ dan tinggi penyangga $60 \mathrm{~cm}$.

Alat sphygmomanometer ini memiliki skala terkecil $2 \mathrm{~cm}$. Karena nilai ketidakpastian adalah setengah dari skala terkecil alat, maka ketidakpastian dari alat sphygmo-manometer ini adalah sebesar $1 \mathrm{~cm}$. Prinsip kerja dari sphygmomanometer aneroid modifikasi ini adalah pada saat alat dipompa, maka alat ukur modifikasi akan menunjukkan angka tertentu (stage), ini dikarenakan oleh tekanan air setinggi h. Sehingga tekanan yang ditunjuk oleh alat adalah tekanan dari zat cair setinggi $h$ yang digunakan. Alat sphygmomanometer aneroid modifikasi ini menunjukkan bahwa semakin besar kedalaman zat cair yang digunakan, maka semakin besar skala tekanan yang ditunjuk pada skala alat sphygmomanometer aneroid. Hasil perhitungan tekanan hidrostatis untuk air maupun minyak goreng diperoleh bahwa semakin besar kedalaman maka semakin besar pula tekanan hidrostatisnya. Dari alat sphygmomanometer aneroid modifikasi ini menunjukkan bahwa pada kedalaman yang sama tekanan hidrostatis air yang dihasilkan berbeda dengan tekanan yang dihasilkan minyak goreng. Perbandingan nilai rata-rata tekanan hidrostatis air dan minyak goreng dari alat sphygmomanometer aneroid modifikasi lebih jelas dapat ditunjukkan pada gambar grafik 1.2.

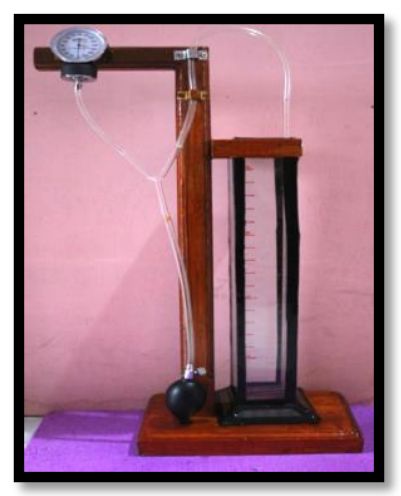

Gambar 1. Sphygmomanometer aneroid modifikasi

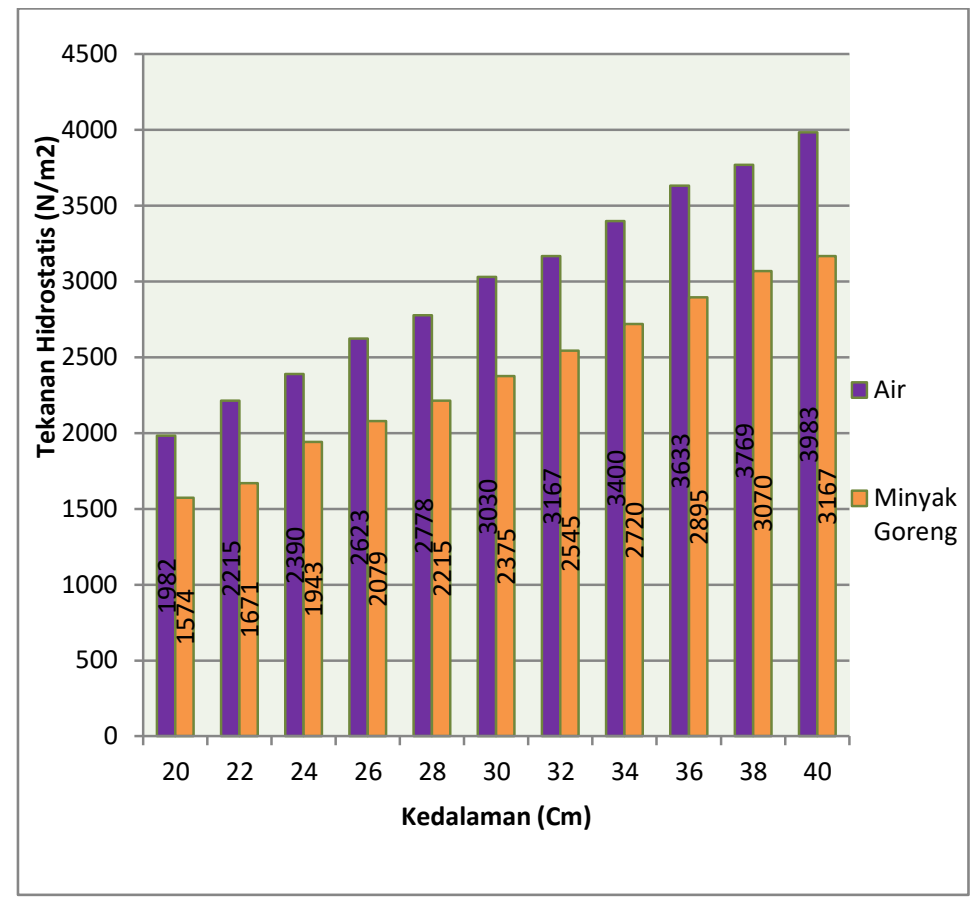

Gambar 2. Grafik Tekanan Hidrostatis Air Dan Minyak Goreng

Gambar 1 menunjukkan bahwa pada kedalaman yang sama tekanan hidrostatis air lebih besar daripada tekanan minyak goreng, ini dikarenakan massa jenis air lebih besar daripada massa jenis minyak goreng. Massa jenis air 
adalah $1000 \mathrm{~kg} / \mathrm{m} 3$ sedangkan massa jenis minyak goreng yang digunakan sebesar 800 $\mathrm{kg} / \mathrm{m} 3$. Secara keseluruhan dari gambar 1.2 diatas menunjukkan bahwa, untuk kedua jenis zat cair yang digunakan dalam hal ini air dan minyak goreng besarnya tekanan hidrostatis bergantung pada kedalaman dan massa jenis zat cair yang digunakan. Besarnya tekanan hidrostatis berbanding lurus dengan kedalaman dan massa jenis yang digunakan, jadi semakin besar kedalaman maka semakin besar tekanan hidrostatisnya. Begitupun dengan besarnya massa jenis, semakin besar massa jenis zat cair yang digunakan, maka semakin besar pula tekanan hidrostatisnya. Hal ini sejalan dengan prinsip hukum utama hidrostatis.

Data nilai tekanan zat cair dari alat yang telah didapat digunakan sebagai data untuk menguji kefektivan alat sphygmomanometer sebagai alat ukur tekanan. Uji efektivitas alat sphygmo-manometer aneroid modifikasi dilakukan dengan membandingkan nilai perhitungan tekanan secara teori dan dari alat sphygmomanometer, untuk melihat adakah perbedaan nilai tekanan keduanya. Uji beda terhadap data nilai tekanan zat cair dianalisis menggunakan uji statistik non-parametrik, dengan uji mann whitney. Hasil uji efektivitas alat melalui uji Mann-whitney menyatakan tidak terdapat perbedaan nilai perhitungan tekanan secara teori dan dari alat sphygmomanometer. Hal ini berarti bahwa alat sphygmo-manometer aneroid ini efektif sebagai alat ukur tekanan hidrostatis, dengan rata-rata nilai asym. Sig $>\alpha(0,05)$. Setelah alat teruji kefektivannya selanjutnya diimplementasikan dalam pembelajaran di kelas eksperimen.

Sebelum pemberian perlakuan pada kedua kelas sampel terlebih dahulu intrumen soal di validasi. Berdasarkan analisis dengan menggunakan lima kriteria yaitu uji validitas ahli, uji validitas empiris, reliabilitas, tingkat kesukaran, dan daya beda soal diperoleh soal yang layak digunakan sebagai pretest dan posttest sebanyak 5 soal. Hasil pretest dari kedua kelas yaitu kelas VIIID dan VIIIE kemudian dianalisis dengan menggunakan uji normalitas dan uji homogenitas dilanjutkan uji beda dengan uji t. Uji beda pada niali pretest dilakukan untuk memastikan bahwa kedua kelas sampel memiliki kemampuan awal yang sama, sedangkan hasil post test siswa akan dianalisis dengan menggunakan uji Mann Whitney untuk mengetahui perbedaan hasil belajar kelas eksperimen dan kelas kontrol. Berikut akan disajikan hasil pretest dan post test siswa untuk kelas kontrol dan kelas eksperimen.

Tabel 1. Data hasil rata-rata tes awal dan tes akhir

\begin{tabular}{|c|c|c|c|c|c|}
\hline \multirow[b]{2}{*}{$\begin{array}{l}\mathbf{N} \\
\mathbf{0}\end{array}$} & \multirow[b]{2}{*}{ Kelas } & \multicolumn{2}{|c|}{ Rata-Rata } & \multirow[b]{2}{*}{ Gain } & \multirow[b]{2}{*}{ Kriteria } \\
\hline & & $\begin{array}{c}\text { Tes } \\
\text { Awal } \\
\text { (Pretes) }\end{array}$ & $\begin{array}{c}\text { Tes } \\
\text { Akhir } \\
\text { (Postes) }\end{array}$ & & \\
\hline 1 & Eksperimen & 33,52 & 76,38 & 0,65 & Sedang \\
\hline 2 & Kontrol & 30,19 & 67,62 & 0,53 & Sedang \\
\hline
\end{tabular}

Tabel 1 menunjukkan bahwa skor rata-rata pretes dan postes kelas eksperimen adalah 33,52 dan 76,38 sedangkan skor rata-rata pretes dan postes kelas kontrol adalah 30,19 dan 67,62. Data diatas menunjukkan bahwa pembelajaran yang diimplementasikan dari penelitian sains dengan model pembelajaran inkuiri terbimbing pada kelas eksperimen mendapatkan rata-rata skor postes lebih tinggi daripada kelas kontrol.

Peningkatan hasil belajar kognitif siswa pada kelas eksperimen dan kelas kontrol dilihat dari nilai $\mathrm{N}$-gain. Nilai $\mathrm{N}$-gain dari skor ratarata pretest dan postest kedua kelas adalah sebesar 0,53 dan 0,65 dari data tersebut dapat dinyatakan bahwa peningkatan hasil belajar siswa pada kelas eksperimen lebih tinggi dibandingkan peningkatan hasil belajar pada kelas kontrol. Hal ini sesuai dengan penelitian Yuli (2015) penerapan model pembelajaran inkuiri terbimbing dapat meningkatkan keaktifan siswa dan penguasaan konsep fisika.

Untuk mengetahui perbedaan hasil belajar kognitif siswa antara siswa yang belajar menggunakan model pembelajaran inkuiri terbimbing dengan siswa yang belajar secara konvensional, dilakukan uji beda terhadap nilai postes kedua kelas. Uji beda pada nilai postest kedua kelas dilakukan uji non parametrik dengan uji Mann-Whitney, karena data postest tidak berdistribusi normal dan tidak homogen. Hasil uji Mann Whitney untuk data nilai postest kedua kelas diperoleh nilai asymp.sig sebesar 0,028 
lebih kecil dari taraf signifikan 0,05 hal ini berarti bahwa terdapat perbedaan yang signifikan antara hasil belajar yang menggunakan model inkuiri terbimbing dengan hasil belajar yang menggunakan pembelajaran konvensional.

Peningkatan dan perbedaan hasil belajar antara kelas eksperimen dan kelas kontrol dipengaruhi oleh beberapa faktor diantaranya penerapan model pembelajaran oleh guru dan penggunaan media atau alat peraga. Pada kelas eksperimen proses pembelajaran dengan menerapkan model inkuiri merupakan sebuah wadah yang sangat tepat untuk meningkatkan keaktifan siswa, karena melalui model pembelajaran ini siswa dapat melakukan kegiatan mengamati, menanya, mencoba, menalar, dan mengkomunikasikan. Selain itu model ini didukung juga dengan metode ekperimen yang mengimplementasikan alat peraga sphygmomanometer aneroid modifikasi yang membuat siswa telibat aktif dalam melakukan percobaan untuk membuktikan konsep-konsep yang dipelajari sehingga siswa dapat lebih mudah memahami konsep dan memungkinkan siswa menguasai tujuan pengajaran menjadi lebih baik.

Hal ini juga sesuai dengan penelitian Lusitadewi dan Prabowo (2012) yang menyimpulkan bahwa dengan penggunaan alat peraga hasil belajar yang dicapai akan tahan lama diingat siswa sehingga hasil belajar yang diperoleh siswa tinggi. Dengan menguasai materi yang dipelajari, siswa mampu menjawab persoalan persoalan yang dihadapi. Maka hal inilah yang dapat meningkatkan prestasi belajar siswa.

\section{KESIMPULAN}

Sphygmomanometer aneroid dapat dimodifikasi untuk dapat mengukur tekanan zat cair (air dan minyak goreng). Nilai tekanan hidrostatis air dan minyak terbesar berada pada kedalaman $40 \mathrm{~cm}$ dengan besar tekanan masingmasing secara berurutan 3982,8N/m2 dan $3166,8 \mathrm{~N} / \mathrm{m} 2$, sedangkan nilai tekanan hidrostatis air dan minyak terkecil berada pada kedalaman $20 \mathrm{~cm}$ dengan masing masing besar tekanan secara berurutan 1981,7 N/m2 dan $1573,7 \mathrm{~N} / \mathrm{m} 2$.

Hasil uji Mann Whitney alat sphygmomanometer aneroid modifikasi efektif sebagai alat ukur tekanan hidrostatis ditunjukkan dengan nilai asymp.sig lebih kecil dari taraf signifikansi 0,05

Terdapat peningkatan hasil belajar kognitif siswa, dapat ditunjukkan pada nilai $\mathrm{N}$-gain kelas ekperimen sebesar 0,65 kategori (sedang) dan nilai $\mathrm{N}$-gain kelas kontrol sebesar 0,53 kategori (sedang)

Terdapat perbedaan hasil belajar antara siswa yang belajar menggunakan model pembelajaran inkuiri terbimbing, dengan siswa yang belajar secara konvensional pada pembelajaran fisika di SMAN 3 Bengkulu Tengah tahun pelajaran 2016/2017 berdasarkan uji Mann whitney diperoleh nilai asymp.sig sebesar 0,028 lebih kecil dari taraf signifikansi 0,05 .

\section{DAFTAR PUSTAKA}

Aziz, A., D.Yulianti dan L. Handayani. (2006). Penerapan Model Pembelajaran Kooperatif Dengan memanfaatkan Alat Peraga Sains Fisika Untuk meningkatkan Hasil Belajar dan Kerja Sama.Jurnal PendidikanFisika Indonesia. Vol.4(2);9499

Balley, R.H.,Knaus dan Bauer. (1991). Aneroid Sphygmomanometers: An Assessment Of Accuracy At A University Hospital And Clinics. Arch Intern Med.1991(151);14091412.

Campbell, N.A., J.B. Reece, dan L. G. Mitchell. (2000). Biologi. Edisi ke-3. Terj. Dari: Biology. 8th ed. oleh Manulu, W. Jakarta: Erlangga.

Canzanello, V. J., Jensen, P. L., \& Schwartz, G. L. (2001). Are aneroid sphygmomanometers accurate in hospital and clinic settings?. Archives of Internal Medicine, 161(5), 729-731.

Fisher, H. W. (1978). Aneroid Sphygmomanometer-Assessment Of Accuracy. Cardiovascular Medicine, 3(7), 769. 
Kametas, N.A., F McAuliffe., E Krampl, dan A H Shennan. (2006). Can aneroid sphygmomanometers be used at altitude. Journal of Human Hypertension, Vol.20 ;517-522

Lusitadewi, F dan Prabowo. (2012). Pengaruh Penggunaan Alat Peraga Sederhana Perpindahan Kalor Sebagai Media Pembelajaran Pada Materi Pokok Kalor Terhadap Prestasi Belajar Siswa Kelas X Di SMAN 1 Gedeg Mojokerto. Skripsi. Surabaya: Universitas Negeri Surabaya. Tidak diterbitkan.

Sanjaya, W. (2007). Strategi Pembelajaran. Jakarta: Kencana Kota Terbit.

Yuli, E. (2015). Lembar Kerja Siswa menggunakan model gided inkuiry untuk meningkatkan ketrampilan berpikir kritis dan penguasan konsep siswa. Jurnal Pendidikan Fisika(JPF). Vol.3:1-15

Zulkarnain, A dan Suliyanah. (2014). Pengaruh Model Pembelajaran Langsung Dengan Pendekatan Inkuiri Terbimbing Terhadap Prestasi belajar Siswa Kelas X pada materi perpindahan kalor di SMA Negeri 1 Wonoayu Sidoarjo. Jurnal Inovasi Pendidikan Fisika (JIPF). Vol.3:70-7 